\title{
Educación despatriarcalizada: clave para la ciudadanía de las mujeres*
}

\author{
María Fernanda Herrera Acuña ** \\ Recibido: 18 julio de 2016 \\ Enviado a pares evaluadores: 21 de julio de 2016 \\ Aprobado por pares evaluadores: 18 de octubre de 2016 \\ Aprobado por Comité Editorial: 24 de octubre de 2016 \\ DOI: 10.22395/csye.v5n10a5
}

\section{RESUMEN}

Las mujeres indígenas y criollas en Bolivia han permanecido desde la conquista bajo un régimen colonial y patriarcal en un vínculo de subalternidad con los hombres. Frente al Estado, en su condición de ciudadanas, han devenido en relaciones capitalistas, modernas y menguadas, luchando desde lo privado y lo público por la búsqueda de equidad, justicia e inclusión. La nueva forma de refundarse el país, Constitución del 2009, ha traído una mirada distinta de transversalidad de género, donde las nuevas políticas educativas ocupan un espacio prioritario para posicionar a las mujeres como sujetos sociales de primera categoría, en cuanto a igualdad, participación y liderazgo.

Palabras clave: género; refundación; educación; Vivir Bien.

\footnotetext{
Texto resultado de formación doctoral en Sociología de la Universidad Alberto Hurtado de Santiago de Chile.

** Licenciada en Filosofía de la Pontificia Universidad Católica de Valparaíso; magíster en Filosofía de la misma universidad; magíster en Educación Superior de la Universidad Mayor de Santiago de Chile. Doctoranda en Sociología de la Universidad Alberto Hurtado de Santiago de Chile. Profesora de la Universidad Alberto Hurtado de Santiago de Chile y de la Universidad Andrés Bello. Ha publicado artículos en diversas revistas latinoamericanas. Correo electrónico: fdaherrera@hotmail.com
} 


\section{Despatriaralization education: key to women's citizenship}

\section{ABSTRACT}

Indigenous and Creole women in of re-founding the country, Constitution of Bolivia have remained since the conquest 2009, has brought a different perspective under a colonial and patriarchal regime; of gender mainstreaming, where the new establishing relationships of subalternity educational policies occupy a priority space with men. In the face of the State, as to position women as first class social citizens, they have become capitalist subjects, namely equality, participation relations, modern and diminished, which they have tried to overcome, from the private and the public; in the search for equity, justice and inclusion. The new way

Keywords: gender; refoundation; education; living well. 


\section{Introducción}

Los procesos feministas en Bolivia -desde la década de los 80-posteriores al regreso a la democracia, y hasta la conformación de la nueva Constitución en 2009 , han vivido un desarrollo de exigencias y replanteamientos que provocaron una serie de cuestionamientos teóricos y reivindicaciones prácticas, en la búsqueda de una mayor integración, presencia y poder con miras a una nueva institución de ciudadanía de género.

Las mujeres, rodeadas y cimentadas en un marco patriarcalista y colonialista institucional, han debido lidiar para refundar un nuevo Estado donde sean consideradas en relaciones horizontales no solo de derecho sino también de hecho, donde su integridad y su presencia sean vistas como factores necesarios y de aportes para gestionar un trato igualitario y en pro de la eliminación de las carencias reales y de su posicionamiento como verdaderas ciudadanas en un espacio público-político inclusivo desde su diversidad y heterogeneidad.

Con esta mirada se realizará un recorrido histórico desde los años 80 hasta la formación de la constituyente, por la presencia activa de las mujeres en la búsqueda de un nuevo situs ciudadano de participación y representación. Luego, se reconocerán los conceptos de patriarcado y descolonialidad como sustentadores de las relaciones de subalternidad en el marco de los géneros.

A continuación, se revisará la importancia del espacio educativo para las incorporación de las mujeres en el cambio ciudadano. Luego, se repasarán los planes y proyectos que el Estado boliviano ha desarrollado para ofrecer una educación con visión de género. Y se finalizará, con las consideraciones sobre la importancia de la educación como intersección y solución a las muchas necesidades del país.

\section{Datos históricos}

En el contexto de la década de los 80 -según el trabajo realizado en el decenio pasado- los grupos de activistas feministas encontraron en la conformación de Organizaciones No Gubernamentales un canal institucionalizado de actuación que bajo la opresión de la dictadura era nulo. Las ONG dotaron de nuevos recursos organizativos al movimiento feminista y muchos de los grupos de mujeres se transforman con el tiempo también en ONG, creándose una serie de asociaciones y colectivos de mujeres en pro de la obtención de un empoderamiento como sujetos individuales y autónomos, en contraposición con la subyugación del espacio privado dominado por la cultura androcéntrica que impone a las mujeres un rol a puerta cerrada dentro del hogar que invisibiliza y, muchas veces, contraría los derechos humanos fundamentales como los de la no violencia, la sujeción económica, la invisibilidad en la toma de decisiones, etc. 
De base y con miras a la sobrevivencia se organizan clubes o centros de madres -en 1987 había cerca de 4000 clubes de madres que involucraban cientos de mujeres, distribuidos en las áreas urbana y rural-relacionados propiamente con su desarrollo y sustentados por agencias y organismos internacionales. Se aplica en estos centros una política de economía, con cuotas y pago de alimentos, transformándose, algunos, en pequeñas corporaciones productivas. A partir de uno de estos centros se formó con apoyo de una ONG, la Asociación de Mujeres Receptoras de Alimentos (1987-1988) con el objetivo de trascender desde lo privado, de la sobrevivencia, al espacio político mediante ciertas demandas de género.

Importante es señalar que a partir de 1981 se suceden los Encuentros Feministas de Latinoamérica y el Caribe, que cada dos o tres años reúnen a las feministas del continente en la reflexión política sobre la situación del movimiento y la elaboración de nuevas líneas de acción, y que tiñen el accionar de las ONG y de los movimientos de mujeres de Bolivia y del resto de Latinoamérica. Junto con estas asociaciones urbanas se crean ciertas organizaciones o colectivos de mujeres campesinas; entre las más destacadas y a nivel nacional, la Federación de Mujeres Campesinas Bartolina Sisa (1983), que nace en el contexto de la recuperación de la democracia en Bolivia y la recomposición de las organizaciones a fin de que las mujeres del área rural participen plenamente de este proceso con una organización propia, organización que mediante cortes de caminos, marchas y huelgas de hambre intenta conseguir autonomía y construir una nueva identidad.

En Bolivia, el movimiento feminista afirma su presencia pública hacia la mitad de la década de los 80; los medios de comunicación se refieren a su existencia e informan sobre los eventos y seminarios que este convoca, difundiendo sus propuestas de agenda.

En 1984 se crea la Coordinadora de Mujeres que agrupa a organizaciones feministas, otras ONG que trabajan con ellas y algunas organizaciones gubernamentales. Se constituye, de este modo, uno de los primeros esfuerzos de concertación entre sociedad y Estado en torno las problemáticas que afectan a las mujeres.

En 1989 se realizó un Congreso Extraordinario en un esfuerzo por unificar diferentes sectores y tendencias políticas que integran el movimiento organizado de la mujer rural; en él participaron alrededor de 200 mujeres en representación de todos los distritos de Bolivia.

En 1989 se crea la Plataforma de la Mujer, que pretende articular el trabajo desde una perspectiva de género y las organizaciones feministas procurando 
lograr la igualdad de la mujer y la democratización en las relaciones cotidianas. Trabaja en la elaboración de reformas y propuestas de ley e inicia una campaña dirigida a la sociedad civil en coordinación con la Comisión de Mujeres del Parlamento para que la violación sea considerada delito público.

La perspectiva de género en la Bolivia, de los años 90, se manifiesta plenamente en organismos gubernamentales, no gubernamentales y en la academia, lo cual produjo una profesionalización del feminismo. Las mujeres y su consigna del derecho a tener derechos, sustentada en movimientos y organismos internacionales, movilizó a colectivos constituidos de mujeres y a las distintas expresiones de las feministas a comprometerse a trabajar alrededor de la urgencia y necesidad de democratizar el poder, la representatividad y la participación en la política en el marco de un ideal democrático de la igualdad como lo sustantivo para ejercer una verdadera ciudadanía, con la finalidad de eliminar inconvenientes tanto sociales y políticos como culturales y económicos, donde la verdadera participación y representación era exclusivo dominio de hombres.

Por tal razón el contexto de los 90 fue favorable para intentar desmontar los arraigados significados culturales de la dominación de las estructuras androcéntricas que, una década antes, las mujeres feministas habían empezado a tematizar y politizar. Ahora se contaba con el concepto de género no solo como un referente para plantear ciertos cambios, sino también, como una nueva interpretación de la realidad donde la igualdad de las mujeres exige nuevas estructuras, símbolos y pertenencias ciudadanas. Frente a este panorama se entrevén como temas en las agendas feministas, la desnaturalización de la exclusión de las mujeres en espacios públicos haciendo visibles los desiguales repartos de poder, la tematización de la violencia contra las mujeres -en espacio de democracia-y la reivindicación de los derechos de las mujeres sobre sus cuerpos.

Frente a estos acontecimientos -en los años 90- la Coordinadora de Mujeres elabora propuestas de políticas sectoriales para incorporar e institucionalizar el género en el aparato del Estado y en la corriente principal de inversión para el Desarrollo.

En 1991 en la ciudad de Santa Cruz de la Sierra, se llevó a cabo bajo la organización de Foro de la mujer (institución que agrupa a varias ONG), el Segundo Encuentro Feminista Boliviano. Se denominó "Segundo", porque en los últimos días de septiembre en 1990, por iniciativa de la institución Tijeras femeninas, se convocó al Primer Encuentro. Según específica la convocatoria enviada a alrededor de 50 ONG, y a otras instituciones dirigidas por mujeres, que se caracterizan por prestar asistencia económica social a otras mujeres, el carácter del Segundo Encuentro, fue el diagnóstico del feminismo en Bolivia. Se completa el Programa del Encuentro remarcando la necesidad de un trabajo 
de género en la búsqueda de autonomía, autoafirmación, autodeterminación y autodirección.

Exactamente un año después, en La Paz, la cifra aproximada de ciento veinte mujeres del Segundo Encuentro se multiplicó a quinientas asistentes al Tercer Encuentro Feminista Boliviano. Asimismo, la organización varió por cuanto se nombró como responsables de dicho evento a ocho instituciones, entre las cuales también se encontraron plataformas que incluyen a otras ONG (como Plataforma de la mujer y Coordinadora de la mujer).

Frente a estos acontecimientos los movimientos feministas en Bolivia se decantan y surgen las institucionalizadas y las autónomas, con estrategias distintas para la transformación y acción de la política. Las feministas institucionalizadas trabajan desde las ONG -lo cual da a sospechar que vestidos con nuevos ropajes los arcaicos organismos internacionales intentaban adueñarse de las nuevas formas de refundación-, y ponen el acento en su capacidad de incidir y negociar con el espacio público estatal, buscando demandar la neutralidad del Estado y desarrollar capital político que pueda incidir en las decisiones públicas (Zabala, 2012). Por su parte, las autónomas o comunitarias apelan a la creatividad como instrumento de luchas, de construcción y realización de utopías y deseos, recobrando la realidad de las conexiones sociales en el marco de la propia vida que rodea a las mujeres para desde ahí trazar un planteamiento imaginativo, un camino de encuentro entre las personas y entre los pueblos, a partir de sus múltiples existencias, con la intención de superar el miedo a las relaciones entre iguales, pero diferentes, y llevar el asombro de descubrir la alteridad de las mujeres como interlocutoras válidas, como un par político representativo en las comunidades. Las mujeres autónomas que participan en los procesos sociales de Bolivia quieren hablar desde sus propuestas como una forma real de abrir un nuevo proceso de lucha para acabar con la opresión. El deseo es plantear la comunidad como la unidad de la sociedad, donde el yo vive comunitariamente con él o la otra, sin dejar de ser sí mismo, dimensionando la subjetividad y la existencia pero abriéndose al otro/a como un igual óntica y ontológicamente. Sobre esto, se plantea no ya el criterio del desarrollo como impulsor de la sociedad, sino el vivir para todas las comunidades, pueblos personas, países. El convivir con la naturaleza: no trabajar con índices sino con la metodología de política pública de los cinco campos de acción y lucha, planteados por el feminismo comunitario en Bolivia, a saber: cuerpo de las mujeres, espacio de las mujeres, tiempo de las mujeres, movimiento organizativo de las mujeres, memoria de las mujeres.

En el año 2000 las organizaciones de mujeres exigen al gobierno de Sánchez de Lozada mantener los mecanismos de género creados bajo el gobierno de Paz 
Zamora. Las características de los contenidos del programa Plan para Todos incluía la reforma del Estado, la modernización económica y nuevas formas de relación entre el Estado y la sociedad, con la idea de posibilitar la descentralización e impulsar la participación social, que generarían las condiciones para redefinir el sentido y alcances de la institucionalidad de género.

Asimismo, entre los años 2000 y 2005 se produce en Bolivia una serie de movimientos sociales donde las mujeres tienen un rol protagónico, que empuja a un feminismo más acérrimo y contundente. Este nuevo período histórico es conocido como Ciclo Rebelde, articulado en las luchas contra las medidas económicas del Estado boliviano. Dicha fase se enmarca en un contexto neoliberal de matriz colonial (Cabezas, 2006). Colonial, porque es la experiencia contemporánea de discriminación racial la que ha servido de elemento catalizador de la memoria histórica colectiva, y de la reivindicación de un pasado glorioso, experiencia que se ha enfocado al empobrecimiento y marginalidad de los pueblos originarios y mujeres de los sectores populares urbanos y del campesinado.

En ese ciclo se produjeron también importantes movimientos sociales con momentos de mucha fuerza y otros de latencia de los cuales hacen parte La Guerra del Agua (2000), el Movimiento Popular de septiembre de 2000, Febrero Negro (2003), la Guerra del Gas (2003), la movilización alteña para expulsar a Aguas del Illimani (2005) y las movilizaciones de junio de 2005; todos ellos con objetivos comunes y que utilizan la rebelión y movimientos socio-políticos para conseguirlos. Revisaremos a continuación los tres primeros mencionados y la presencia femenina en ellos.

La guerra del Agua del 2002 no fue solo una acción motivada por el alza de los precios del servicio de agua de Cochabamba contra las empresas transnacionales, sino también, contra la ineptitud del Gobierno referente a la pobreza y a la crisis económica sufrida por Bolivia en los procesos de privatización (Anónimo, 2001), donde hubo una masa notable de mujeres. En Bolivia y particularmente en Cochabamba, los derechos de agua para diversos usos -agua potable, riego, bebedero de animales- son un derecho familiar que puede ser reclamado por cualquier persona, no solo por el jefe de hogar. Durante las movilizaciones, la gente de los barrios marginales de la ciudad y de las comunidades campesinas se desplazó hacia la ciudad para apoyar en los bloqueos y las marchas que mantuvieron aislados a varios sectores de la población. Durante el conflicto, las mujeres participaron activamente: en sus hogares, en las calles, frente a las fuerzas policiales y autoridades; desde los flancos más cotidianos y necesarios -organización de víveres, mercadeo de provisiones y ollas comunes- hasta los más cívicos.

También, participaron llevando piedras, alambres y otros, como delegadas o jefas de bloqueo y en responsabilidades de vigilancia y control hasta el cum- 
plimiento y revisión de las disposiciones de la Coordinadora y Federación de Regantes de Cochabamba (Fedecor).

En este escenario, las mujeres urbanas y rurales experimentaron diversas vivencias según el espacio donde se encontraban. Para las féminas del campo el conflicto implicó grandes sacrificios porque durante los períodos más agudos tuvieron que movilizarse dejando abandonados sus hogares. También sufrieron en principio reacciones de maltrato y discriminación en la ciudad. No obstante, a medida que el conflicto se iba intensificando y generalizando, la actitud de la población, principalmente de los estratos sociales medios y altos, fue cambiando hasta confluir en acciones de solidaridad entre los sectores urbanos y rurales. Sin embargo, esta unidad alrededor de reivindicaciones comunes pone en un segundo plano pero no elimina, las reivindicaciones de género, ya que si bien las mujeres eran parte activa de los levantamientos, no ocurría lo mismo en el nivel de las instancias de dirección donde se tomaban las decisiones y se actuaba como interlocutor del Gobierno. Terminado el conflicto, las mujeres consideran que su experiencia les ha generado nuevas expectativas e intereses:

[...] entonces yo ya no quiero quedarme en mi casa, quiero participar porque también tengo el mismo derecho. Entonces por eso hay que comenzar a organizarse, las mujeres debemos capacitarnos...hay fuerzas para poder participar y aprender. Somos fuertes a lo menos en nuestras comunidades ya no tenemos miedo, nos aprovisionamos de nuestros alimentos como tostados, (cereales) quesos, charques (carne de res deshidratada) y vamos nomás a la lucha (Urjta, 2008, on line)

El antecedente inmediato de la Guerra del Gas fue el levantamiento popular denominado Febrero Negro, cuando se vislumbraba e descontento del sector indígena-popular y la desproporcionada represión militar del Gobierno de Sánchez de Lozada.

Como protesta la policía se amotinó y el Gobierno mandó al ejército a controlar el orden público y la propiedad privada. Entre los días 12 y 13 de febrero tuvo lugar una violenta manifestación de descontento social, coincidente con la visita de una delegación del FMI a Bolivia; en ella se produjeron 32 muertos y 214 heridos, en su mayoría fruto de enfrentamientos entre la policía y el ejército. Uno de los sucesos más fuertes del Febrero Negro fue el asesinato, por parte del ejército, de la enfermera Ana Colque, donde resultó también gravemente herida una médica, cuando ambas acudían a socorrer a un albañil herido. En el levantamiento popular, la población quemó y saqueó varios edificios públicos y las sedes de los partidos políticos tradicionales. En el Alto se quemaron la Alcaldía y la sede de Aguas de Illimani (Cabezas, 2006).

En la Guerra del Gas no se hicieron diferenciaciones entre hombres y mujeres. No obstante, se percibió una fuerte participación femenina en ciertos momentos 
de su accionar, a saber, la instancia intermedia de jefes de calle y comités de movilización, y la iniciativa de los propios vecinos de base (Flores, Herbas y Huanca, 2006) quienes se encargaron de convocar por calles a los vecinos. Pero hubo una instancia mucho más participativa que no estaba prevista ni siquiera por las propias juntas vecinales: la organización autónoma vecinal. En este nivel se reconoce una igualitaria participación femenina. Hubo mujeres dirigentas informales, que convocaron a marchas y bloqueos, a la defensa del barrio y de las familias.

Todo este escenario se enmarca en la demanda por la Asamblea Constituyente-inaugurada en agosto del 2007- donde se espera impulsar un nuevo pacto social que permita renovar la legitimidad del Estado y ampliar la democracia para dar cabida a nuevas identidades étnicas, culturales y nuevos actores sociales como las mujeres, quienes piden participación y reconocimiento (Zavala, 2012).

Conceptos involucrados tras las peticiones de las mujeres: patriarcalismo y colonialismo

Las demandas promovidas por las mujeres en el contexto de la exigencia por una nueva institución de su ciudadanía no son menores dentro de la legitimidad de Bolivia, pues, los cambios que se esperan no responden solo a una situación de empobrecimiento o falta de derechos esenciales -que ya es prioritaria- sino a una reestructuración misma del Estado, a una nueva forma de articular la nación. No son sino las mujeres quienes por medio de sus colectivos, organizaciones, trabajos institucionalizados y autónomos pretenden desarmar viejos conceptos arraigados en la constitución de Bolivia, a saber, el patriarcalismo y el colonialismo. Esta tarea no fácil de construir, pues la disputa se presenta ya no con las circunstancias del aquí y el ahora, sino, con todo el andamiaje que ha sostenido, hasta ahora, la forma de establecer e interpretar las relaciones sociales, políticas, económicas, culturales y de género.

Cuando se habla de patriarcalismo se está haciendo referencia a un

[...] sistema de relaciones sociales sexo-políticas basadas en diferentes instituciones públicas y privadas y en la solidaridad interclases e intragénero; el patrimonialismo ha sido instaurado por los varones, quienes, como grupo social y en forma individual y colectiva, oprimen a las mujeres, también en forma individual y colectiva ,y se apropian de su fuerza productiva y reproductiva, de sus cuerpos y sus productos, ya sea con medios pacíficos o mediante el uso de la violencia (Fontenla, 2008, on line)

Esta definición que, prima facie, parece clara y contundente debe ser, no obstante, desarticulada para entender las profundas raíces de sometimiento y subalternación en las que se encuentran las mujeres. A partir del feminismo radical la expresión "relaciones sociales sexo-políticas" debe ser entendida 
como relaciones políticas por medio de las cuales, los varones dominan a las mujeres (Millet, 1975). Al decir: "están basadas en diferentes instituciones públicas y privadas" hace referencia al dominio masculino sobre la familia, es decir, las mujeres e hijos y, por lo mismo, la extrapolación de tal dominio sobre las mujeres en lo global de la sociedad (Lerner, 1995). Entre otras instituciones fundamentales se encuentra el Estado, pues el hombre recibe en su formación, de manos del pater familis, el poder sobre los demás miembros de la familia. Desde ahí el Estado coloca en una relación de sujeción a las féminas respecto a los varones, negando y dificultando su constitución como sujetos políticos autónomos. Al hablar de "solidaridad interclases e intragénero instaurado por los varones", se refiere a la hermandad entre hombres, quienes se confabulan espontáneamente para dominar a las mujeres (Hartmann, 1987). Apropiación de la fuerza reproductiva de las mujeres es la visión del feminismo materialista, que concierta la fuerza productiva a la reproductiva y los productos al cuerpo de las mujeres.

Una cultura de base patriarcal trae serias consecuencias para las mujeres como sujetas de derecho, desiguala, diferencia y discrimina la realidad mujer frente a la sociedad en su universalidad, lo que frustra las expectativas de sociabilidad como seres autónomos y valientes, recalca una jerarquía de los hombres y, por lo mismo, disminuye la persona misma de ser mujer y cualquier tipo de aporte que intente realizar. Bolivia, como la mayoría de los países de Latinoamérica, se encuentra subsumida y abigarrada de patriarcalismo. Cualquier intento de asumirse como ciudadana con legítimos derechos pasa por borrar, de alguna manera, la impronta patriarcal de su cultura, tarea titánica si se piensa que su constitución como Estado, tanto en el discurso como en su narrativa, se establece bajo un género masculino.

Ahora bien, otro de los conceptos que limitan el desarrollo de la mujer, en su búsqueda de relaciones igualitarias o complementarias con los hombres, es el de colonización o, su contrario, el de descolonización. El término de colonización está enlazado estructuralmente con la Modernidad que dispone y predispone una lectura de la realidad vinculada con la razón científica, discursiva e instrumental, pues la colonización no es sino la utilización de la razón para el dominio, manejo o aplicación del poder foráneo que produjo paradigmas desfigurados de conocimiento y malogró las promesas liberadoras de la Modernidad. La matriz colonial de poder, sustentada en la propia diferencia, entiende al colonizador o civilizado como superior al exterior, al de afuera o bárbaro, implantando, en la realidad, estructuras de supremacía sobre lo conquistado, donde una etnia particular se impone como cosmovisión racional. A partir de esto, surge el término des-colonial que pretende a partir de aquello otro o exterior una liberación epistemológica para dar paso a una nueva comunicación inter-cultural, a un 
intercambio de experiencias y de significaciones como base de otra racionalidad que pueda pretender con legitimidad alguna universalidad.

Por ese motivo, para implementar una ciudadanía con identidad de género es menester situarse en el contexto espacio geográfico donde se realiza, en este caso en Bolivia, lo que exige un entendimiento propio de la cultura real existente desde siempre. Proceder a un discurso o a una narrativa con paradigmas cognitivos y hermenéuticos externos es no entender el contexto, situación y problemáticas a resolver. Por esto, descolonizar es leer desde lo propio no solo las diversidades existentes entre los sujetos, sino tanto desvelar como plasmar una política que conlleve las raíces originarias del espacio social donde se convive.

La descolonialidad exige superar la codificación colonial de la diferencia del ethos de la objetivación y universalización que domina el pensamiento moderno. Frente a esta representación neocolonial las mujeres reclaman su consideración como sujetos de acción política para la construcción de avances en su autonomía y dignidad, a partir, de sus propios contextos culturales. Dicha tarea solo puede llevarse a cabo desde el pensamiento crítico de quienes se encuentran frente a múltiples exclusiones. La experiencia personal del dolor y la marginación por la falta de adecuación a las categorías dominantes requiere tanto de teoría como de política, pues, para descolonizar se debe atender a revelar el complejo de superioridad occidental como subyugación de otros: mujeres originarias, indígenas y campesinos, que forman parte sustancial de la sociedad (Suárez y Hernández).

\section{Superación para la desigualdad de género: la educación}

El proceso refundatorio en Bolivia exige construir una ciudadanía capaz de enfrentar los nuevos retos, con igualdad y justicia, ciudadanía que entienda, bajo una mirada de equidad e inclusión, los importantes cambios civilizatorios por los cuales atraviesa el Estado en la búsqueda del Bien Vivir. Si el Suma Qamaña se entiende como el encuentro entre pueblos y comunidades, respetando la diversidad e identidad cultural, en una convivencia comunitaria, con interculturalidad y sin asimetrías de poder; significa que "no se puede vivir bien si los demás viven mal, vivir bien en armonía... significa... vivir en equilibrio con lo que nos rodea... vivir bien contigo y conmigo" (Coquehuanca, 2010), lo cual implica una realización afectiva, subjetiva, intelectual y de disfrute, en armonía con la naturaleza y en comunidad con y entre los seres humanos, a saber, hombres y mujeres.

El proceso de descolonialidad no puede entenderse, prioritariamente, sin una despatriarcalización de las relaciones humanas. Despatriarcalizar es aceptar al "otro" no solo en la igualdad sino también en su diferencia, con toda la riqueza 
que esto conlleva; es subsanar aquellas diferencias específicas, entre los géneros, que constituyen una constante e importante característica estructural en las distintas sociedades.

Descolonizar y despatriarcalizar el género no es solo recuperar aquella identidad oscurecida y perdida, en los principios de la dominación extranjera, sino es volver a construir un colectivo donde la mirada política posibilite los lineamentos y narrativas que configuren un marco de adaptación para la factibilidad real de una nueva institucionalidad que potencie pensamientos, epistemes, paradigmas e inclusiones nuevas, donde un espacio fundamental de lineamiento y políticas públicas es dado por la educación, que ayuda a la autoconstitución como sujetos y ciudadanos distintos con miras a las nuevas formas de reconfiguración política. Esta nueva educación no es una negación de lo legado sino una afirmación de que hombre y mujer pueden aportar desde su propia perspectiva resurgiendo de las dominaciones capitalistas de poder y supremacía de unos contra otras. Es decir, posibilita una nueva forma de entender y crear una identidad original y originaria, que recupera lo que se ha sido y lo que se es para proyectarlo en una dualidad de género aumentado y complementario

Se trata de entender cómo relacionarse con el otro sin cosificarlo ni estigmatizarlo como distinto a lo propio. El ser humano se constituye en relación con la otredad y, ese otro no es solo una moción hacia lo intercultural en un Estado plurinacional -en contextos multiculturales, como Bolivia, los pueblos indígenas y afrodescendientes tienen perspectivas particulares propias que tienen que ser incluidas en un diálogo intercultural para aportar a desarrollar una sociedad con equidad no solo étnica sino también de género-, sino hacia la profundización de lo intracultural, que permite una reconstitución de mi legado y mi estar para conformar una construcción común. La educación refundadora tiene que contener esos vínculos de la intraculturalidad del sujeto, en cuanto género, pues el proceso de diálogo intergenérico funda otra autoconstitución y, por tanto, otra forma de Estado.

Por esto, educar desde la refundación es constituir sujetos ciudadanos y ciudadanas en un paralelo ontológico de equidad, cuya representatividad sobrepase, para estas últimas, el mero dominio de lo privado y se proyecte hacia una participación en lo público con una influencia directa de ellas. Donde su estar en el mundo devenga en el ejercicio igualitario de sus derechos civiles. Superar aquella perspectiva de separación entre la esfera de la sociedad civil-política y la esfera privada de la familia, que sellaba un pacto entre democracia y patriarcado es dejar de excluir, en cuanto ciudadanía, a la mitad de la humanidad. La educación con visión de género debe superar, entonces, la visión de aquel individuo -las mujeres- ensimismadas y despojadas de todo atributo social, 
cuya única característica dominante es su pertenencia a la especie humana (Zúñiga, 2010). Solo en la medida en que hombres y mujeres participen, decidan y se proyecten en igualdad de condiciones, será posible la construcción de una cultura democrática y un desarrollo sustentable.

\section{Aportes de la educación refundadora}

Bolivia ha enfrentado el tema de la refundación con visión de género, ya desde la Constituyente, como un factor indispensable para el logro del Suma Qamaña y del desarrollo inter e intra-cultural. Con una visión transversal ha intentado ingresar el tema de la equidad entre los sexos desde diversos enfoques. Si bien, la Carta Magna no menciona en su ideario la despatriarcalización como propósito o concepto (Ybarnegaray, 2011), el Estado ha creado una serie de instancias que se ocupan de trabajar el tema género y concretarlo en diversas políticas públicas que ayudan a la inserción con equidad ciudadana; entre ellas cabe mencionar el Viceministerio de Descolonización, dependiente del Ministerio de Culturas, entre cuyas atribuciones destacan el desarrollo de políticas para la prevención y erradicación de toda forma de discriminación, racismo, xenofobia e intolerancia cultural. En este Viceministerio se ha creado la Dirección General de Lucha contra el Racismo, de la que depende la Unidad de Despatriarcalización, la misma que tiene como misión despatriarcalizar el Estado colonial y neoliberal, las familias, la sociedad y la religión. Entre sus objetivos se encuentra el de visibilizar, desestabilizar, poner en crisis las relaciones patriarcales y transformar las relaciones de poder existentes en el Estado plurinacional para constituir una sociedad justa y armoniosa.

Al mismo tiempo, se ha fundado el Viceministerio de Igualdad de Oportunidades, que es la cabeza del sector para el diseño y la aplicación de las políticas públicas destinadas a eliminar todas las formas de discriminación contra las mujeres. La normativa generada desde esta instancia es de cumplimiento obligatorio para todo el sector público, incluido el nivel departamental a través de las Direcciones Departamentales de Género o las Unidades Departamentales de Género.

En el campo de la educación, la Nueva Constitución Política del Estado, en su artículo 17, establece que "toda persona tiene derecho a recibir educación en todos los niveles de manera universal, productiva, gratuita, integral e intercultural, sin discriminación", entendiéndola como un derecho humano y un elemento indispensable para el progreso social y económico, se reconoce la necesidad del acceso pleno en condiciones de igualdad como un requisito fundamental para la potenciación de la mujer y un instrumento primordial para lograr los objetivos de políticas públicas con visión de género (Bruner, 2011). Por lo cual, la 
educación "constituye una función suprema y primera responsabilidad financiera del Estado, que tiene la obligación indeclinable de sostenerla, garantizarla y gestionarla" (art. 77, I).

En el contexto latinoamericano, Bolivia muestra los indicadores educativos más rezagados. La población femenina, especialmente, "la que vive en zonas rurales, es la que más dificultad representa". Si bien, la situación educacional ha mejorado apreciablemente en las últimas décadas, sigue siendo en desmedro en comparación a los hombres, desnivel marcado por un contexto educativo que muestra deficiencias vinculadas a tres factores principales: la raza, la estratificación social y, por supuesto, el género (Ortiz, 2013). Esta última perspectiva llevó a aprobar, por Decreto Supremo, 29850 (2008), el Plan Nacional de Igualdad de Oportunidades: Mujeres Construyendo la Nueva Bolivia, para Vivir Bien, que establece los lineamientos generales para aplicar políticas públicas con igualdad de oportunidades entre hombres y mujeres, lineamientos entre los cuales destaca el eje educación con las siguientes políticas (Anónimo, 2012):

1. Erradicar el analfabetismo femenino.

2. Incrementar las oportunidades de acceso y la permanencia de niñas, adolescentes y jóvenes mujeres en el sistema de la educación formal y alternativa.

3. Incorporar la perspectiva de género en la revolución educativa.

4. Abrir oportunidades de formación, capacitación y profesionalización de las mujeres en todos los ámbitos.

\section{Educación y mujer, hoy}

1. El analfabetismo afecta mayormente a las mujeres (19\%) sobre todo a las campesinas e indígenas, en comparación con sus pares varones (7 \% y 14 $\%$, respectivamente). En 2001 -año del último censo realizado en Bolivia-en el área rural, el 39,3 \% de las mujeres no había alcanzado ningún nivel de instrucción. En el área urbana el 10,5 \% de las mujeres no tiene ningún nivel de instrucción.

El enfoque de género, en cuanto al analfabetismo y la educación de adultos, se incorpora a partir de promover relaciones de equidad y respeto entre mujeres y hombres sin discriminación, favoreciendo la autodeterminación. Promover y privilegiar la educación de mujeres tanto en alfabetización como en Educación Primaria y Secundaria de adultos tiene una positiva visión hacia la participación activa de las féminas en sus procesos educativos. Igualmente se trabaja, en cuanto a los contenidos, una clara intención de género al no invisibilizar a las mujeres y no diferenciar a hombres y féminas 
con una valoración y respeto de iguales a partir de sus diferencias (Ministerio de Educación y Cultura).

En lo concreto, respecto a ciertas innovaciones en la alfabetización, se han desarrollado la bi-alfabetización quechua-castellano y el método masivo y medio audiovisual, alfa-numérico "Yo sí puedo" que, basado en la antropología social de Paulo Freire, asume como postulados fundamentales la diversidad cultural y la unidad psíquica del ser humano, enfatizando el desarrollo de capacidades de comprensión y empatía entre los y las participantes, además del respeto a las diferencias de etnias.

2. En Bolivia, la concentración de la oferta educativa está en el área urbana. En el área rural se evidencia una casi inexistencia de centros de Educación Superior. El sistema educativo nacional ha segmentado el acceso por condición étnica; reforzando los sesgos de género de la educación moderna, en el área rural y la desvalorización de las prácticas educativas de los pueblos originarios.

La educación ha registrado avances en la matrícula escolar del primer ciclo, que subió y, prácticamente, cerró la brecha entre hombres y mujeres. En los ciclos superiores, persisten las relaciones asimétricas de género, agudizados en la zona rural. La educación de las mujeres, en las áreas rurales, se expresa, más que nada, en instrucción, hecho que no ha logrado revertir la inequidad de las diferencias de género, que se reproducen en los niveles superiores (Cabrero, 2007).

No obstante, la situación de las niñas en la Educación Primaria, en el acceso y permanencia, ha mostrado cambios importantes. Así, por ejemplo, en el área rural, la matrícula femenina de la gestión de 2006 muestra una leve evolución hacia la equidad de género respecto a la gestión 2005; mientras que en el área urbana crece lentamente. En el ámbito de la educación secundaria, el área rural detenta el más bajo índice de acceso escolar. En el área urbana, si bien es mínima la matrícula masculina y femenina, se ha observado un leve aumento en los últimos años. En cuanto, al nivel superior, el censo del año 2001 señala que el 13,10 \% de mujeres alcanza el nivel de Educación Superior frente a un 16,7 \% de hombres. En el área urbana el 18,62 $\%$ de mujeres alcanza el nivel superior y en el área rural es de 2,34\%.

Ahora bien, la permanencia de niñas y niños en el sistema educativo se encuentra condicionada por dos factores: uno, por la pobreza rural que exige la migración de las familias hacia lo urbano, y otro, por la permanencia de las niñas dentro de la educación formal citadina, quienes por bajas condiciones económicas y sociales deben abandonar la escuela para ingresar al mundo 
laboral. Estos dos factores han sido acometidos con diversos programas de recuperación de escolaridad, tales como el proyecto de Acceso y Permanencia de las niñas rurales en la escuela -componente del Convenio 3096 del Proyecto de Fortalecimiento a la Calidad y Equidad de la Educación de la Reforma Educativa Boliviana- desarrollado en el Ministerio de Educación por el Viceministerio de Educación y el Proyecto Niña Trabajadora dirigida a menores en situación laboral, respectivamente. En lo rural la finalidad del componente es contar con un Plan de Acción que favorezca el acceso y la permanencia de las niñas en la escuela rural, y que proporcione insumos para contar con una política educativa a favor de la educación de las niñas. Desde el inicio el objetivo a largo plazo del componente señalaba impulsar el acceso y permanencia de las niñas en las escuelas del área rural a través de la generalización de estrategias de intervención exitosas y sostenibles, y promover un cambio de actitud en la comunidad educativa respecto a la participación de las niñas del nivel primario en la escuela (Ministerio de Educación-Bolivia, 2005). En lo citadino, los programas ayudan "a retener en la escuela a los estudiantes en riesgo de abandono" donde se realizan transferencias en efectivo (a sus beneficiarios) "material escolar, transporte escolar, hospedaje y alimentación", y en algunos casos acompañamiento pedagógico y psicológico, atención básica en salud, capacitación laboral, actualización informática o fortalecimiento de derechos y de identidad (Anónimo, 2012).

No obstante, siguen existiendo insuficientes mecanismos de acceso, permanencia e igualdad de oportunidades para las mujeres en la educación. Un sistema educativo deficiente que no cuenta con mecanismos de acceso, permanencia e igualdad de oportunidades para mujeres y hombres, y que está sustentado en una cultura sexista y estereotipada que restringe las posibilidades educativas y laborales de las mujeres.

3. Respecto a la Educación Superior en la medida que la población ha ido creciendo la Educación Superior aumenta. "El acceso de las mujeres se muestra en un porcentaje total del $47 \%$, se considera un porcentaje importante ya que no existen políticas referidas a este grupo. En general no se encuentran políticas sobre Educación Superior que involucren el acceso a la Educación Superior de grupos vulnerables".

4. En el segundo mandato de Evo Morales, aumentaron las oportunidades y profesionalización de las mujeres en todos los ámbitos; desarrollándose programas prioritarios como los siguientes: el Programa de Capacitación y Formación Integral de Jóvenes bolivianos, apuntado a mejorar los perfiles socio-productivos de la población de áreas del altiplano y de valles 
interandinos de Bolivia a través del desarrollo de competencias laborales, productivas y sociales y de la generación de empleos y emprendimientos productivos, la Instalación de Telecentros Educativos Comunitarios. Los Telecentros Educativos Comunitarios son espacios físicos que permiten a los alumnos de Unidades Educativas y a la comunidad en general el acceso a las tecnologías de información y comunicación, para apoyar al desarrollo educativo, trabajar en el desarrollo particular o comunitario, en aspectos sociales, económicos, políticos, culturales, etc. (Ministerio de Educación y Culturas-Bolivia, 2006).

Estas directrices del Estado boliviano intentan no otra cosa que, dentro del ámbito educativo, estandarizar las oportunidades existentes para repartirlas de manera justa entre ambos sexos. Solo la educación es capaz de brindar los instrumentos de los que hombres y mujeres se sirven para construir sus experiencias, sus saberes, alimentar su lucha, sus movimientos y sus espíritus. Por esto, los hombres y las mujeres deben contar con las mismas oportunidades de desarrollo desde su niñez, en un contexto de inclusión, equidad y paz que posibilite el florecimiento de todas sus aptitudes y creatividades con miras al bienestar común, al Vivir Bien. Vivir con espacios de dignidad y posibilidades, cuya meta no sea solo una educación formal teñida de género, sino un verdadero locus de co-habitar donde la presencia del otro sea un aporte en la propia realidad; ambos con las herramientas necesarias para entender que solo en la diversidad de género, de raza, de situaciones, está la verdadera riqueza del país.

\section{Consideraciones finales}

La desigualdad de género es un problema no solo para las mujeres que lo padecen, sino para el país en su totalidad. Un Estado que discrimine la participación ciudadana de un grupo importante de individuos es un Estado arcaico y suspendido. No puede existir desarrollo y avance sin la inclusión de todas las miradas de una sociedad.

El Estado boliviano se ha hecho cargo de esta situación y ha devenido en la implementación de una serie de políticas públicas y proyectos, de nivel nacional, que intentan romper la brecha de exclusión existente entre sus mujeres y sus hombres, posibilitando un sistema educacional que desde los inicios detente una mirada de género, no solo para la nueva cepa que está en formación, sino también, para reparar las falencias de alfabetismo e inequidad escolar existente desde antaño.

La tarea no es fácil cuando lo que se intenta abarcar va más allá de la sola educación formal, pues se deben suplir, al mismo tiempo, otros tipos de dife- 
rencias que separan y profundizan las inequidades del sistema educacional, a saber: los contrastes existentes entre lo rural y la ciudad, las desigualdades de distribución, las faltas de oportunidades tecnológicas, etc. El Estado boliviano, no obstante, ha entendido que todas estas variables no pueden ser superadas sin una mirada distinta y refundatoria del proceso educativo. Es por medio del educar donde hombres y mujeres pueden encontrarse frente a ellos mismos y en la arena pública como ciudadanos preparados y participantes.

\section{Notas}

1. El origen del movimiento CMCC (CMCC) se remonta en parte al año 1990, cuando Julieta Paredes y su entonces pareja María Galindo regresaron a La Paz después de vivir algún tiempo en Italia. En 1992 ambas fundaron en la capital boliviana, junto a Mónica Mendoza y otras mujeres, el movimiento feminista autónomo denominado Mujeres Creando.

2. La llamada "Corriente Autónoma" se instala públicamente hace 17 años, en 1993, en el Encuentro Feminista Latinoamericano y del Caribe realizado en El Salvador, cuando Cómplices, una colectiva feminista compuesta por mexicanas y chilenas, puso a dar vueltas en el feminismo latinoamericano el libro Feminismos Cómplices, gestos para una cultura tendenciosamente diferente (1993).

\section{Bibliografía}

Anónimo, (2001). Bolivia: La visión y participación de las mujeres en la guerra del agua en Cochabamba Bolivia, Obtenido el 10 de marzo de 1014 de http://www.es.genderandwater.org/content/ download/7384/50648/file/Estudio\%20de\%20caso\%204\%20Bolivia.pd

Arnold, D; Spedding, A, (2005). Mujeres en los movimientos sociales en Bolivia 2000-2003, La Paz, CIDEM: ILCA

Bruner Joaquín, Hurtado Rocío (2011), Educación Superior en Iberoamérica (Informe 2011), Santiago, CINDA.

Bolivia, Ministerio de Justicia- Viceministerio de Género y Asuntos Generacionales (2008). Plan Nacional para la Igualdad de Oportunidades "Mujeres Construyendo la Nueva Bolivia para Vivir Bien", La Paz. Bolivia, Ministerio de Educación (nd), Bolivia: programa de Alfabetización Yo sí puedo. La Paz.

Bolivia, Ministerio de Educación (2005). Proyecto Hemisférico. Elaboración de Políticas y Estrategias para la Prevención del Fracaso Escolar, Buenos Aires: UNSAM.

Bolivia, Ministerio de Educación y Culturas (2006). Tecnologías de la Información y Comunicación para el fortalecimiento del sistema educativo y el desarrollo comunitario. Programa Nacional de TIC, La Paz.

Cabezas M, (2006) iA Chonchocoro!, Testimonios de mujeres bolivianas afectadas por la "guerra del gas", Barcelona: ACSUR-Las Segovias. 
Cabrero, Elizabeth (2007). Situación de los derechos económicos, sociales y culturales con enfoque de género en Bolivia, La Paz: Celade.

Choquehuanca, D. (2010). 25 postulados para entender el Vivir Bien, La razón 2010. [Versión impresa] Obtenida el 10 de marzo de 2014, de https://groups.google.com/forum/\#!topic/revolucion-org-ve/ uMrQU0w8T60

El acceso a la educación y la permanencia escolar es más difícil en zonas urbanas (2012, 31 DE Enero). Periódico digital de investigación sobre Bolivia [versión impresa]. Obtenida el 10 de mayo de 2014, dehttp://www.pieb.com.bo/sipieb_notas.php?idn=6506

El Plan Nacional de Igualdad de Oportunidades "Mujeres construyendo la nueva Bolivia para vivir bien" (2012, 8 de Marzo). Obtenido en 10 de mayo de 2014, de http://www.opinion.com.bo/opinion/ articulos/2012/0308/noticias.php?id=46982

Flores J, Herbas I, Huanca F; (2006). Participación política de mujeres alteñas en las acciones colectivas y en la vida cotidiana, La Paz: PIEB.

Fontenla, Marta, (2008). Diccionario de estudios de género y feminismo, México: Ed. Biblos.

Hartmannn, Heidi, (1987). El infeliz matrimonio entre marxismo y feminismo, Cuadernos del Sur N. 5, marzo, pp. 113-158, Buenos Aires.

Lerner, G. (1990). La creación del patriarcado, Barcelona: Ed. Crítica.

Martínez, Alejandra y Ferreiro, Yolanda, (2011). Los sistemas de acceso, normativas de permanencia, y estrategias de tutoría y retención de estudiantes de educación superior. La Paz: Accedes.

Millet, Kate, (1975), Historia de la mujer argentina, Tomo III, Buenos Aires: Ed. Aguilar.

Ortiz, Vanessa, (2013), Modelos estéticos hegemónicos, subalternos o alternativos: una perspectiva étnico-racial de clase y género. Colombia, Buenaventura: Universidad del Pacífico.

Suárez, Liliana, Hernández Roslava, (s.f). Descolonizando el feminismo. Teorías y prácticas desde los márgenes, Obtenido el 10 de marzo de 2014, de http://webs.uvigo.es/pmayobre/textos/varios/ descolonizando.pdf

Urjta (2008) Recuperado el 19 de abril de 2017. http://urjta.blogspot.cl/2008/09/la-lucha-de-las-mujeresen-bolivia.html

Ybarnegaray, Jenny (2011). Feminismo y descolonización. Notas para el debate [versión impresa]. La Revista Nueva Sociedad N. ${ }^{\circ}$ 234, julio-agosto de 2011, pp. 159-171.

Zavala, M. (2010). Los objetivos de la Lucha: de las cuotas hacia una política de presencia. Obtenida el 10 de mayo de 2014, de http://www.eclac.org/publicaciones/xml/3/6323/lcl1511e.pdf

Zúñiga Añazco, Yanira. (2010). Ciudadanía y Género: representaciones y conceptualizaciones en el pensamiento moderno y contemporáneo [versión impresa]. Revista de Derecho Coquimbo, V. 17 n. 2 , pp. 133-163. 
